\title{
ALCANCE Y LÍMITES DEL PRINCIPIO DE PROPORCIONALIDAD
}

\author{
SCOPE AND LIMITS OF THE PRINCIPLE OF PROPORTIONALITY
}

\author{
Dr. Juan Carlos Riofrío Martínez-Villalba*
}

RESUMEN: El presente trabajo analiza el alcance y los límites del principio de proporcionalidad en el derecho comparado, desde una perspectiva abstracta-metafísica y con una metodología inductiva. Debido a que su extensa aplicación en la práctica no siempre ha sido muy correcta, la investigación procura definir cuál es el sentido original del principio y cuáles son sus límites. Se pasan revista a tres clases de límites, en su orden: 1. los presupuestos de aplicación del principio (llamados límites a priori), sin los cuales sería irracional aplicarlo; 2. los límites del funcionamiento del principio que, o bien son límites internos imputables a su mal funcionamiento, o bien son límites externos producidos por factores extraños a la proporcionalidad como la irrazonabilidad del juez; y, 3. los límites a posteriori de aplicar correctamente el principio, palpables cuando este no produce todos los efectos esperados.

Palabras clave: Proporcionalidad, principios del derecho, límites de los principios, alcance de los principios, razonabilidad.

ABSTRACT: This paper discusses the scope and limits the principle of proportionality in comparative law, from an abstract-metaphysic perspective and with an inductive methodology. Because their extensive practical application has not always been very successful, this research seeks to define what is the original meaning the principle and what their limits are. Three kinds of limits, in that order are studied: 1. preconditions for applying the principle (called a priori limits), without which it would be unreasonable to apply; 2. limits in the operation of the principle, that could be internal limitsattributable to some malfunction of the same principle, or external limitsproduced by strange things, like an unreasonableness judge; and, 3. limits that operate a posterioriof the correct application, that appears when the principle does not produce all the expected effects.

Key words: Proportionality, principles of law, principles limits, principle scopes, reasonability.

\section{INTRODUCCIÓN}

Procuramos desentrañar en estas líneas cuál es el alcance y los límites del principio de proporcionalidad en el derecho comparado, desde una perspectiva abstracta-metafísica ${ }^{1}$. Para el efecto recurrimos a una metodología inductiva que extrae de una multitud de casos el ámbito donde opera este principio y sus limitaciones. Pero como su aplicación no siem-

\footnotetext{
* Profesor titular de Derecho constitucional y de filosofía del Derecho, Universidad de Los Hemisferios (Quito, Ecuador), Dirección postal: Paseo de la Universidad No 300 y Juan Díaz - Iñaquito Alto. Dirección electrónica: jcriofrio@gmail.com, juancarlosr@uhemisferios.edu.ec

${ }^{1}$ El presente trabajo se enmarca dentro de un proyecto de investigación de metafísica jurídica promovida por la Universidad de Los Hemisferios.
} 
pre ha sido homogénea, ni se ha entendido lo mismo por proporcionalidad en todo tiempo y lugar, debemos comenzar esta investigación definiendo cuál es el sentido original del principio, como a continuación hacemos.

\section{ORÍGENES Y SENTIDO DEL PRINCIPIO}

La aplicación del principio de proporcionalidad (también llamado "de razonabilidad") ha ido conquistando progresivamente relevancia en la jurisprudencia constitucional de la mayoría de ordenamientos jurídicos, tanto del derecho continental, como del anglosajón. No obstante, el tan invocado principio rara vez encuentra pie en la norma escrita. Como dice Gavara, "el principal problema que plantea la aplicación del principio de proporcionalidad en sentido amplio (...) es la no previsión de su aplicación el texto constitucional" 2 .

$\mathrm{Su}$ introducción en la jurisprudencia ha tenido una compleja -cuando no forzosa- justificación. En Alemania, por ejemplo, se lo instauró invocando el "Estado de derecho" que lleva en su seno la idea de limitación de los poderes públicos en favor de los ciudadanos $^{3}$. En España se ha justificado en aras del "valor justicia" ${ }^{4}$, de "la dignidad de la persona" y de la "interdicción de la arbitrariedad de los poderes públicos" ${ }^{\text {. En Estados }}$ Unidos la doctrina de la restricción desmesurada de derechos fue fruto de la evolución del due process of law (consagrada por la Enmienda XIV de la Constitución) que en 1869 comenzó a entenderse también en sentido sustantivo ${ }^{7}$. Otros países como Argentina ${ }^{8}$ anclan este principio en la garantía de no restricción legal de los derechos fundamentales.

En casi todos los países la proporcionalidad nació como un remedio contra los excesos en los que incurrían las decisiones tomadas por el Poder Legislativo y por el Poder Ejecutivo ${ }^{9}$. Una ley arbitraria no es derecho, ni tampoco un acto administrativo que restringe desproporcionadamente los derechos de los ciudadanos. Bajo estos parámetros el Tribunal Constitucional alemán descompuso la proporcionalidad en tres subprincipios destinados a controlar una medida (v. gr. una ley, una decisión general, un acto administrativo de efectos generales, etc.) emanada de un sujeto con potestad (v. gr. el representante del Poder

\footnotetext{
2 Gavara de Cara (1994) p. 313.

3 Gavara de Cara (1994), p. 314. En Alemania "el principio de proporcionalidad tiene rango constitucional. Se deriva del principio del Estado de derecho, en razón de la esencia misma de los derechos fundamentales que, como expresión de la libertad general de los ciudadanos frente al Estado, no pueden ser limitados por el Poder Público más allá de lo que sea imprescindible para la protección de los intereses públicos" (BverfGE, n 19, p. 348).

4 Sentencias 160/1987, FJ 6º; 50/1995, FJ 7o; 173/1995, FJ, 2º.

5 Sentencia 160/1987, FJ 6º, donde también se apela a la noción de Estado de derecho.

6 Sentencias 6/1988, FJ 3o; 50/1995, FJ 7o.

7 En este sentido consta un obiter dictum en Hepburn v. Griswold, 8 Wall. 603 (1869), que luego el Tribunal aplicó en 26 casos durante la década 1877-1887. A partir de ahí se extendió su uso. WiLloughby \& RogERs (1924) pp. 65, 391-392.

8 Tal garantía se encuentra en los arts. 28 y 33 de la Constitución Nacional de Argentina. Al respecto, cfr. Cianciardo (2009a) pp. 40-47.

9 Cfr. Cianciardo (2009a) pp. 33-62; Lopera (2006) pp. 31-32.
} 
Ejecutivo, el Parlamento, alcalde u otra autoridad), en cuanto esta medida se considera desproporcionada, irrazonable, innecesaria e inadecuada.

La proporcionalidad no nació para controlar otras violaciones de derechos fundamentales o humanos perpetradas por personas privadas, ni para solucionar conflictos entre particulares. Tampoco el principio fue creado para detectar todo lo que es arbitrario, antijurídico o contrario a la razón. Una ley puede ser irracional no solo por exigir de los ciudadanos conductas innecesarias o desproporcionadamente onerosas, sino también por ser contradictoria en sus postulados, por contradecir la cultura local o simplemente por violentar un derecho constitucional indisponible. No todo lo irracional es irrazonable o desproporcionado ${ }^{10}$.

Pero como el principio nació sin una definición normativa o jurisprudencial preci$\mathrm{sa}^{11}$, no siempre resulta claro cuándo conviene aplicar el principio, qué cuestiones se encuentran fuera de juego y cuáles son sus límites. Hoy, por ejemplo, encontramos autores que distinguen de manera irreconciliable el principio de proporcionalidad, de otros principios como los de ponderación, razonabilidad y proporcionalidad estricta ${ }^{12}$, mientras otros identifican algunos pares ${ }^{13}$, o lo consideran una subespecie de ponderación o balanceo ${ }^{14}$. A la vez, en las últimas décadas el principio ha ido expandiendo su radio de acción a terrenos donde inicialmente no se preveía su aplicación ${ }^{15}$.

A fin de acotar el tema, y dado que las cortes constitucionales suelen identificar hoy este principio con el diseñado por el Tribunal Constitucional alemán (con sus tres subprin-

10 En cambio, si vale decir que todo lo irrazonable, arbitrario o desproporcionado es irracional.

11 En este sentido, cfr. Cianciardo (2009a) p. 62.

12 Cfr. Ávila (2011) pp. 128-157, quien lo distingue del principio de justa proporción que opera sin tomar en cuenta el fin; del de ponderación de bienes que sopesa valores pero de forma diversa al razonamiento de la proporcionalidad que relaciona medio y fin; del de concordancia práctica que exige la máxima realización de los valores superpuestos, sin ninguna referencia al modelo medio-fin; del de prohibición de exceso que vela por una protección mínima de derechos; y del principio de razonabilidad, que puede operar sin mención alguna a la proporción entre medios y fines, pp. 147-148.

13 Cfr. Cianciardo (2009a) pp. 86-92. Se ha criticado a Shlink de reducir el principio de proporcionalidad a dos subprincipios (excluyendo la proporcionalidad estricta), porque tal modelo "no sería aplicable a supuestos de casos en los que el juicio de adecuación y necesidad no sean suficientes para determinar la prioridad de un derecho frente a otro en un caso determinado. Este sería el caso de los denominados "casos difíciles". PORTOCARRERo (2011) p. 66. Sobre el tema, cfr. SCHLInK (1976) p. 144 y (2001) pp. 458-462; Stelzer (1991) pp. 49 y ss.; DA Silva (2003) p. 162; STERn (1994) pp. 865 y ss.

14 Cfr. Zúniga (2010) pp. 260-261. Arnold, Martínez Estay \& Zúñiga Urbina (2012) p. 66, consideran que la idea de razonabilidad abarca la proporcionalidad, con lo que entre ambos principios existe una relación de género a especie.

15 En concreto, parte de la doctrina ha sustituido los derechos absolutos por este principio absoluto. Alexy ha manifestado que en los derechos fundamentales el uso de este principio resulta inevitable porque "no hay otro modo racional en el que la razón para limitar puede ser puesto en relación con un derecho fundamental" (AleXY (2002) p. 74), mientras Beatty lo considera como un "criterio universal de constitucionalidad" (AleXY (2004) p. 162). Un buen referente sobre la suficiencia de la proporcionalidad y su amplio uso se encuentra en KLAtT \& Meister (2012), tema que solo dejamos señalado y que se encuentra fuera de nuestros objetivos. 
cipios de necesidad, idoneidad y proporcionalidad estricta) ${ }^{16}$, analizaremos aquí los límites del principio de proporcionalidad de cuño alemán.

\section{CLASES DE LÍMITES}

Sin duda, no somos los primeros en hablar de los límites del principio de proporcionalidad. Varios autores al analizar su noción y objeto de aplicación terminan señalando, un poco de pasada, las limitantes de su aplicación. Sin embargo, rara vez se ha tratado el asunto de sus límites de manera sistemática.

Nosotros encontramos que existen tres tipos de límites ${ }^{17}$ que hacen inoperable el funcionamiento del principio de proporcionalidad: 1. los límites a priori que funcionan antes de aplicar el principio, determinan su alcance y están relacionados con sus presupuestos, sin los cuales no podría operar; 2. los límites del funcionamiento del principio que, o bien son límites internos imputables a su mal funcionamiento, o bien son límites externos producidos por factores extraños a la proporcionalidad como la irrazonabilidad del juez; y, 3. los límites a posteriori de aplicar correctamente el principio, palpables cuando este no produce todos los efectos esperados.

Esta clasificación muestra cómo cada género de límites tiene consecuencias diversas. En concreto:

1. La presencia de límites a priori ocasiona una inaplicabilidad del principio. Es decir, si no se dan los presupuestos del principio, no cabe aplicarlo.

2. La presencia de límites internos ocasiona que el principio no arroje ningún resultado (v. gr. el caso del empate valorativo), o que únicamente arroje resultados probables o dudosos (v. gr. cuando aparecen elementos difíciles de mesurar).

3. La presencia de límites externos ocasiona un déficit de certeza en la aplicación del principio. Esto ocasiona un tortuoso funcionamiento de la proporcionalidad y unos resultados faltos de certeza.

4. La presencia de límites a posteriori ocasiona una inaplicabilidad parcial de las conclusiones extraídas del principio, que no cabe aplicar a ciertos casos actuales y futuros. A continuación los tratamos con detalle, en su orden.

\footnotetext{
16 Sobre la influencia de este principio en Europa y América, cfr. Covarrubias (2014) pp. 163-237; Arnold, Martínez-EstaY y ZúñIga Urbina (2012) pp. 65-116. Los tres últimos autores, sin embargo, distinguen cuatro cuestiones que examina la proporcionalidad: “a) Debe perseguir una finalidad legítima. b) Debe ser adecuada o idónea para la promoción (no necesariamente la realización) de dicho objetivo legítimo (geeignetheit o adecuación). c) Debe ser necesaria, y entre varias alternativas de intervención debe preferirse la que afecte menos a los derechos involucrados (mínimo de intervención). d) Debe ser proporcional en sentido estricto”. Con todo, cabe unificar los dos primeros elementos.

17 Usamos la noción de "límite" en su amplio sentido filosófico, como contorno, demarcación o frontera de algo. Nuestro objetivo es delimitar el ámbito de aplicación, uso y validez del principio de proporcionalidad. La definición de "límite" es discutida en derecho. Algunos solo consideran los límites fácticos (basados en los hechos, la fuerza mayor o el estado psicológico), mientras otros incluyen dentro del concepto los límites normativos; finalmente otro sector de la doctrina abre una puerta a los límites axiológicos, morales o culturales. Sobre la cuestión, cfr. pp. ABRIL (2007) pp. 551-572. La noción que aquí utilizamos recoge estos tres tipos de límites e incluye otros aspectos adicionales, como los presupuestos esenciales de aplicación del principio o su rango de eficacia.
} 


\section{PRESUPUESTO DE APLICACIÓN}

Resulta de crucial importancia determinar cuáles son los presupuestos necesarios para que el principio de proporcionalidad opere. Una aplicación indebida del principio a casos para los cuales no fue diseñado generaría resultados inconsistentes, contradictorios y hasta peligrosos.

Haciendo un paralelo de la tradicional clasificación de causas (que divide las causas en material, formal, eficiente y final ${ }^{18}$ ), aparece que el principio de proporcionalidad tiene un objeto final, formal y material, así como una causa eficiente, que definen dónde opera. Pasaremos revista de cada uno de estos elementos, que funcionan como presupuestos de la aplicación del principio. Basta que falte uno de ellos para que el principio torne en inoperante, o para que su aplicación resulte cuestionada.

\section{a) OBJETO FINAL}

El objeto final es la finalidad para la cual el principio ha sido creado. La metafísica advierte que el fin es la causa más importante de todas: la causa causarum, la razón que dota de sentido a todo, aquello que justifica el resto de causas. ¿Por qué se creó el principio de proporcionalidad? Como vimos, su aparición en la jurisprudencia alemana se debió a la necesidad de controlar los excesos en los que incurrían las decisiones de los poderes públicos.

Repárese que la proporcionalidad funciona no solo como regla hermenéutica que permite dar una correcta lectura a un texto normativo o de un principio positivado, sino también como una técnica mental supranormativa (porque está por encima de las leyes e impera sin necesidad de que conste explicita en el texto constitucional) que controla la razonabilidad del orden jurídico. Ávila considera al "postulado de la proporcionalidad” como "norma de segundo nivel" 19 ubicada en un metanivel superior a las reglas y a los principios consagrados en las normas.

Hay fines más próximos y más lejanos. Como todo principio intelectual el de proporcionalidad busca llegar a la verdad. La verdad es el objeto natural del intelecto; la inteligencia no tiene otro objeto. El principio "controla" la racionalidad de las leyes descubriendo sus excesos, evidenciando aquello que resulta irrazonable, volviendo palpable lo que es desproporcionado. Todo esto es el fin inmediato del principio intelectual. Pero además cabe descubrir un fin más lejano.

El principio de proporcionalidad no tiene fines meramente didácticos: no busca evidenciar lo irrazonable solo con ánimos eruditos. Por el contrario, su fin ulterior es controlar que las decisiones de la autoridad sean razonables. Este control primero debe hacerlo la misma autoridad pública a la hora de dictar sus propias normas; luego los ciudadanos veri-

\footnotetext{
18 Hacemos este paralelo admitiendo que la causalidad no opera de modo idéntico en todos los seres, aunque tampoco de manera totalmente desigual. Las causas funcionan de modo distinto en el cosmos, en el ser personal, en el ser intencional. Cada acto de ser tiene su forma de causar, según la intensidad de su ser. Aunque el principio de proporcionalidad tenga base in re, su quididad es eminentemente intencional: propiamente es un hábito intelectual. Por eso las cuatro causas clásicas descubiertas por los griegos en el cosmos solo aplican a los entes intencionales de manera analógica.

19 Ávila (2011) pp. 144-157.
} 
ficarán si la norma es soportable; finalmente el juez podrá declarar imperativamente que la medida es irrazonable y que debe tenerse por inexistente, nula, inválida, ilegítima, inconstitucional o contraria a derecho.

Arbitrariedad y derecho son dos conceptos contrapuestos. Ahora bien, no siempre aparece claro qué decisiones son arbitrarias y cuáles están justificadas. Además, ha de recordarse la presunción de legitimidad de las decisiones de la autoridad ${ }^{20}$. Por eso, en general conviene que ninguno tome justicia por mano propia y que sea el juez quien controle la proporcionalidad y haga caer formalmente aquello que tiene apariencia de derecho. Sin embargo, cuando la arbitrariedad sea sumamente patente ante todos los ciudadanos, ninguno estaría llamado a cumplir la medida irrazonable. Ahí no haría falta tumbar formalmente la apariencia de derecho que no existe. Parafraseando a Radbruch, diríamos que "una media sumamente irrazonable jamás es derecho”.

\section{b) OBJETO FORMAL}

Todo lo que existe tiene una forma, también los entes intencionales como el principio de proporcionalidad. La forma de este principio es justamente "la proporcionalidad" o "razonabilidad" de la medida sub iudice. Pero, atención, no se confunda esta "proporcionalidad" con el término genérico de "proporción", ni menos el "principio de proporcionalidad" nacido en la jurisprudencia alemana con las diversas proporcionalidades que hay en otras ramas del derecho. Se habla, por ejemplo, de la proporción entre culpa y pena en el derecho punitivo, de las cuotas proporcionales del derecho electoral, o de la proporcionalidad de los cargos entre hombres y mujeres.

La proporcionalidad pergeñada por la jurisprudencia constitucional alemana solo aplica cuando hay un "fin" (que debe ser legítimo ${ }^{21}$ ) y una "medida" (que debe adecuarse al fin, ser necesaria y proporcionada ${ }^{22}$. Sin estos dos extremos, los tres exámenes de adecuación, necesidad y proporción estricta simplemente resultarían incomprensibles. De estos dos extremos, el que marca la pauta (el que primero bosqueja "la forma", en sentido metafísico) es el fin. Las avenidas se trazan para llegar a un lugar, las medidas se adoptan para conseguir un objetivo. Tanta primacía tiene el fin, que si se descubre una medida más idónea y menos lesiva de conquistarlo, la vieja medida estará llamada a caer.

Vale detenerse en la legitimidad del fin y de la medida. Contra lo que dice un engañoso aforismo ${ }^{23}$, el fin no justifica cualquier medio. Nunca será proporcionado alcanzar un fin usando medios ilegítimos. Incendiar las fábricas tabacaleras para mejorar la salud de los

\footnotetext{
20 El principio de legitimidad de los actos administrativos ha sido extensamente comentado por autores como Bosch, Linares, Bielsa, Diez, Spota, Marienhoff, entre otros. Por todos, cfr. Gordillo (2004) pp. 145-180.

21 Como afirma Cianciardo (2009a) p. 65, después de glosar la jurisprudencia española (sentencias 55/1996, FJ 7o; 111/1993, “R.T.C.”, t. 1993-I, p. 1239, FJ 90) y la del Tribunal Europeo de Derechos Humanos (casos García Manibardo vs. España, sentencia de 15-II-2000, \$ 36; News Verlags GmbH and CoKG vs. Austria, sentencia de 11-I-2000, $\$ \$ 44-46$ ), el juicio de adecuación implica que "a) debe existir un fin; b) el fin no debe estar prohibido constitucionalmente; y c) el fin debe ser socialmente relevante. Esto último no se exige de modo uniforme en todos los países (...)".

22 En este sentido, cfr. Ávila (2011) pp. 144-145.

23 El aforismo "el fin justifica los medios" solo hace sentido cuando significa que el medio existe en razón del fin, de tal manera que si por cualquier motivo desaparece el fin, el medio pierde su razón de ser. Como dice
} 
fumadores, robar a los ricos para dar a los pobres, torturar para obtener la confesión de un delito, serán siempre per se medidas desproporcionadas.

Varios doctrinarios han entrevisto lo irrazonables que resultan las leyes ilegítimas. Por ello Toller ${ }^{24}$, Sapag ${ }^{25}$ y otros autores ${ }^{26}$ han considerado conveniente añadir a los tres subprincipios clásicos de la proporcionalidad (los de adecuación, necesidad y proporcionalidad estricta), uno adicional que consistiría en un juicio de respeto del contenido esencial de los derechos regulados. Aceptando plenamente tan aguda observación, consideramos que sería aún más apropiado y completo exigir -mediante un test o subprincipio- que la medida en sí misma sea legítima en derecho, en todos los aspectos imaginables. Tanto el fin, como la medida deben ser legítimos. Actualmente hay un test para analizar la legitimidad del fin, pero no se ha completado el test que indaga la legitimidad de la medida ${ }^{27}$.

La mencionada legitimidad de la medida faltaría no solo cuando atentara contra el núcleo fundamental de los derechos regulados, sino también de los derechos no regulados directamente (v. gr. cuando acaece el factum principis), o cuando la medida transgrediera una norma superior, o sea dictada por autoridad incompetente, o violente irremediablemente otros principios fundamentales como el de igualdad, dignidad, etc. En todos estos casos parece claro que la medida ilegítima es, a la vez, desproporcionada. Un secretario de un juzgado que de manera incompetente emitiera una orden de prisión, o un juez que sentenciara cadena perpetua donde estuviera proscrita, a todas luces actuarían de manera irrazonable, arbitraria y desproporcionada. Redactado al estilo anglosajón, el test podría sintetizarse en la siguiente pregunta: ¿̨la medida adoptada es inconciliable con el núcleo de algún derecho fundamental en juego, o con algún fin, valor, principio o norma superior ${ }^{28}$ ? Si fuese inconciliable, la medida habría de tenerse como ilegítima.

Un tema clásico en la materia es el de la intensidad del control que el Poder Judicial puede realizar sobre el Legislativo y el Ejecutivo. ¿Hasta dónde los jueces están facultados

Rhonheimer (2000) p. 388, si el fin no justifica el medio, ¿qué lo justifica? Sin embargo, el mismo autor señala que "el fin no justifica los medios", es decir, no justifica usar "cualquier" medio, sino solo medios legítimos.

24 Toller (2012) pp. 148-152, habla del (i) test de la existencia de la finalidad; (ii) test de la constitucionalidad o legitimidad del fin; (iii) test de la adecuación de los medios; (iv) test de la necesidad de los medios; (v) test de proporcionalidad de los medios; y, (vi) test de no afectación del contenido esencial del derecho regulado. Observa que "así como el test 2 mira expresamente a la legitimidad del fin, el test número 6 se focaliza expresamente en la legitimidad del medio, que ya ha sido tocada, parcialmente en los test 3 y 5 " (Toller (2012) p. 151).

25 Cfr. SAPAG (2012) pp. 171-206, donde sugiere cinco test o subprincipios: (i) el juicio de finalidad; (ii) el juicio de adecuación; (iii) el juicio de necesidad; (iv) el juicio de proporcionalidad (en sentido estricto); y, (v) el juicio de respeto al contenido esencial de los derechos regulados.

${ }^{26}$ V. gr. CianCiardo (2009a) pp. 114-117 que habla sobre el juicio de alteración o afectación del contenido esencial; Maldonado (2012), que sigue a Sapag.

27 Por eso, hoy "una medida proporcionada puede hacer sucumbir los derechos fundamentales" CovarRubias (2012) p. 460. El autor citado se muestra favorable a la tesis planteada de incluir en la proporcionalidad el deber de proteger el contenido esencial de los derechos (MaLdonADo (2012) pp. 462-470).

${ }_{28}$ Ciertamente los fines, valores y principios, así como el núcleo esencial del derecho, serán más difíciles de definir qué lo previsto en blanco y negro por las normas superiores. Sin embargo, no podemos desconocer la multitud de medidas que son ilegítimas, no por atentar a lo literal de la ley, sino por contrariar los fines, valores, principios y derechos fundamentales, mencionados o no en las normas superiores. Por ello, no podemos reducir este test a la mera inconstitucionalidad de la medida adoptada. El desarrollo de estas ideas amerita un espacio más amplio, del que aquí carecemos. 
para controlar la razonabilidad de sus decisiones? Un importante fallo de la Corte Suprema argentina ha señalado que "los jueces tienen el deber de formular juicios de validez constitucional, pero les está prohibido basarse en juicios de conveniencia; si el más alto tribunal hace esto último, desplaza a los poderes políticos y se convierte en una "superlegislatura"29. Esta es precisamente una de las grandes críticas que se formulan al principio de proporcionalidad: so capa de aplicar la constitución, los jueces hacen decir al texto constitucional lo que nunca ha dicho, y justifican con razones políticas (de conveniencia, no de necesidad jurídica) lo que consideran mejor ${ }^{30}$.

El principio de proporcionalidad judicial tiene el objetivo formal de determinar la "proporcionalidad en derecho" o la "razonabilidad jurídica" de la norma sub iudice, no su "razonabilidad política”. En lo político suelen darse múltiples opciones justas o legitimadas por el derecho, cualquiera de las cuales el legislador puede optar según motivos de conveniencia. En el mundo jurídico se tiene derecho o no se tiene derecho, algo es justo o no lo es, la acción es permitida (como facultativa o como obligatoria) o prohibida ${ }^{31}$. Así, si el legislador optó por cualquier opción legítima, el juez constitucional no podría invalidar la ley aduciendo una escasa conveniencia de la medida adoptada, o una mala ponderación de valores, principios o derechos en juego. En cambio, cuando la norma se adoptó contra derecho (v. gr. violentando el núcleo duro de los derechos constitucionales o un pilar fundamental del ordenamiento), solo entonces el juez será competente para invalidar tal norma por desproporcionada ${ }^{32}$. De otra manera el juez se convertiría en el legislador o administrador más autorizado del país, echando por tierra la emblemática división de poderes.

29 “Montalvo", Fallos, 313: 1333 (1990): 79 (45), voto de la mayoría, considerando 9.

30 En este sentido Schlink señala que "la jurisdicción constitucional no es una parte constitutiva de la política, sino su contraparte dotada de legitimación y racionalidad propias” (SCHLINK (2001) p. 462), para concluir que debería excluirse a la ponderación del principio de proporcionalidad por su alto grado de subjetividad e irrelevancia al momento de evaluar la afectación de los derechos fundamentales. Y LEISNER (1997a) pp. 636-639; LEISNER (1997b) pp. 170 y ss.) presagiaba que con estos principios pronto se pasaría del "Estado de derecho" al "Estado ponderativo", criticando concretamente que "en el lugar de las grandes políticas partidarias entra, de la mano de la ponderación y del principio de proporcionalidad, una política partidaria fina y disimulada; en dicha política el funcionario público y el juez reemplazan a los parlamentarios y gobernantes (...)" por lo que "el juez tiene que pensar en leyes y en la ponderación el razonamiento del juez no es más que política” LeISNER (1997b) p. 72.

31 Son oportunas las palabras de Hervada, quien al hablar de las leyes distingue "una perspectiva propia de filosofía política, esto es, de una contemplación de la convivencia humana en función de su desenvolvimiento correcto (que es lo propio de la filosofía política). Pero no es la perspectiva jurídica (si por perspectiva jurídica entendemos la del arte del derecho, o sea la de lo justo), porque lo jurídico es lo propio del ius o iustum; la norma es jurídica en función del ius o derecho (en sentido realista). La perspectiva jurídica no es la del orden social, sino la del reparto de las cosas. (...) Dicho sintéticamente, reciben el nombre de normas jurídicas aquellas normas que se refieren a conductas justas, esto es, a conductas que son debidas -obligatorias- porque constituyen un deber de justicia conmutativa, de justicia distributiva o de justicia legal; una norma es jurídica, cuando la conducta que prescribe constituye una deuda justa" Hervada (2001) pp. 134-135, a donde reenviamos para una ampliación de lo dicho).

32 Destacamos que ni el ejecutivo, ni el legislador, ni el juez están obligados a adoptar la "medida más conveniente" y "menos restrictiva" de derechos, intereses, pretensiones, etc. de los ciudadanos. Basta que se escoja una solución legítima o justa. Cfr. Ávila (2011) pp. 156-157; CiAnCiardo (2009a) pp. 92-95, quien además señala que "no cabe exigir la realización total del fin buscado: basta una aptitud o posibilidad de cumplimiento parcial”, p. 78. Cfr. sentencia 34/1983, FJ 3º. 
El problema aquí radica en que la frontera entre lo "razonable en derecho" y lo "políticamente razonable" no siempre está nítidamente marcada. Existen casos en donde resulta evidente que hay una proporcionalidad jurídica o no la hay. Manifiestamente injusta sería la prohibición absoluta de fumar tabaco para mejorar la salud de la sociedad; en cambio, serían justos los mandatos de advertir sobre los efectos nocivos para la salud, la limitación de los lugares de venta de tabaco, las restricciones en la publicidad, etc. Pero además hay una zona gris donde no resulta claro si la razón de proporcionalidad es de orden político o jurídico, como sucede con la limitación impuesta a una fábrica de producir solo una cuota de tabacos (que probablemente violenta el principio de libertad de empresa), o una restricción fuerte de distribuir tabaco mientras se facilita la distribución de droga (lo cual podría transgredir del principio de igualdad).

Por lo dicho, cuando es claro que solo existe una salida justa o legítima, entonces huelga aplicar el principio de proporcionalidad. Si la norma superior señala una sola posibilidad válida y la autoridad pública la adopta, sería vano entrar a analizar la proporcionalidad de la medida para concluir su validez (en todo caso, habría que cuestionar la razonabilidad de la norma jerárquica). Menos aún hará falta revisar la proporcionalidad de las normas que contrarían flagrantemente el derecho superior. Por ejemplo, si el legislador expresamente quitó a la Fiscalía General funciones atribuidas por la constitución, o desconoció el procedimiento administrativo regulado por la norma superior, o no reconoció el núcleo esencial de algún derecho fundamental cuando estaba expresamente obligado a hacerlo (por ejemplo, tipificando alguna pena proscrita por la ley fundamental), entonces la norma debe tenerse, sin más, como espuria. En tales casos, resultaría superfluo -y quizá hasta contraproducente- entrar al complejo análisis trifásico de la proporcionalidad.

\section{c) OBjETO MATERIAL}

El objeto material es la materia que el principio analiza, la cosa que se juzga, a saber: la medida de autoridad pública. Tal "medida" -medio destinado a alcanzar un fin- puede ser: una ley, un reglamento, una norma de cualquier tipo, así como un acto administrativo o una interpretación vinculante, e incluso una sentencia de juez inferior ${ }^{33}$.

Históricamente el principio de proporcionalidad no nació para controlar los actos de simple administración ${ }^{34}$, ni las decisiones de las autoridades privadas, ni el ejercicio de los derechos constitucionales, ni mucho menos los negocios privados. Es cierto que como recurso intelectual el principio sirve para evidenciar la irrazonabilidad del informe de un perito, o la arbitrariedad de un empleador que exige a sus obreros ver una hora diaria de televisión, o lo irrazonable de una huelga armada para exigir al jefe el festejo de los cumpleaños, o lo desproporcionado de una permuta que cambia una botella de whisky por un

\footnotetext{
33 Corresponde al tribunal ad quem analizar si el juez a quo aplicó de manera correcta en su sentencia el principio de proporcionalidad.

34 El concepto es usado en varios países. En el Ecuador, por ejemplo, se los ha definido a estos actos como "toda declaración unilateral interna o interorgánica, realizada en ejercicio de la función administrativa que produce efectos jurídicos individuales de forma indirecta en vista de que solo afectan a los administrados a través de los actos, reglamentos y hechos administrativos, dictados o ejecutados en su consecuencia" (Estatuto de Régimen Jurídico, Administrativo de la Función Ejecutiva, art. 70).
} 
automóvil. Sin embargo, no parece que esté en manos de la justicia constitucional controlar las decisiones que violenten los actos de simple administración, que por su falta de firmeza no ponen directamente en juego derechos constitucionales, ni normas de rango superior. Tampoco está llamada a controlar las decisiones de las autoridades privadas (v. gr. jefes editoriales, gerentes de empresa, presidentes estudiantiles, rectores de universidades, padres de familia, etc.) porque las autoridades privadas tienen un ámbito mayor de libertad -incontrolable por la justicia constitucional- que las autoridades públicas ${ }^{35}$. Gozan del mismo ámbito de extensa libertad los negocios privados, donde en general cada quien puede disponer sobre lo propio. Algo semejante ha de decirse del ejercicio de los derechos constitucionales, pues el principio de proporcionalidad no se diseñó pensando en aquellos supuestos; si se desea aplicarlo a estas situaciones habría que repensar la arquitectura trifásica del principio ${ }^{36}$. Y todavía más absurdo sería que los jueces entren a controlar la proporcionalidad de todas las medidas tomadas en la intimidad familiar ${ }^{37}$.

\section{d) Sujetos (CAusa eficiente)}

El agente (causa eficiente o agente ${ }^{38}$ ) del principio es el quien "actúa" aplicándolo. En concreto, es el juez y el operador del derecho que aplica el principio para los fines antes mencionados. "Operador del derecho" en primer lugar es la autoridad pública que al dictar la norma debe revisar que esta sea razonable. También es operador del derecho el sujeto pasivo llamado a cumplir tal norma, que está interesado en evaluar si la norma es arbitraria. Tanto el juez, como el operador del derecho, están llamados a aplicar el principio de proporcionalidad, aunque en momentos distintos: primero corresponde hacerlo a la autoridad al momento de dictar sus reglas, actos administrativos, políticas, etc.; luego al perjudicado para evaluar el daño; finalmente corresponderá hacerlo al juez cuando se haya iniciado un proceso para controlar la proporcionalidad de la medida.

\footnotetext{
${ }_{35}$ Por el principio de clausura, en el derecho privado se permite hacer todo lo que no está legalmente prohibido, mientras en el derecho público solo cabe hacer lo facultado por la ley.

36 Una sugestiva aplicación del principio de proporcionalidad al ejercicio de los derechos fundamentales es la formulada por Toller (2012) pp. 152-153. Pero para tal cometido, Toller no se limita a aplicar los tres subprincipios clásicos (que él entiende deben ser seis; vid. nota 19) a una norma que no existe, sino que rediseña la proporcionalidad. Primero convierte las pretensiones de las partes en "hipotéticas normas"; luego pasa los seis test de proporcionalidad a cada una de las hipotéticas normas; finalmente se determina cuál derecho es real y cuál el imaginario. El autor afirma haber obtenido resultados satisfactorios al analizar de esta manera el derecho a la huelga frente al derecho a la educación.

37 Existe una cierta intangibilidad de las acciones privadas que no afectan el orden público, que las saca del control judicial. Cfr. Maldonado (2014) pp. 9-48. Si afectaran a los derechos de terceros, la cuestión sería distinta. Con todo, habría que dejar a salvo el principio de subsidiariedad que confiere una cierta primacía a las familias para las decisiones que naturalmente les competen.

${ }^{38}$ Según Aristóteles la causa eficiente es "aquello de lo que primeramente proviene el cambio" (Física II, 7, 198 a 25). Bajo esta noción, la causa eficiente comprende tanto la acción productora del cambio, como el sujeto que la realiza que se presenta como el agente del cambio. Por eso, "a ese complejo de sustancia y acción es a lo que se llama también "agente" GARCíA López (1995) p. 259. La causalidad eficiente puede dividirse de diversos modos: total o parcial, causada o incausada, universal o particular, unívoca o análoga, principal o instrumental, necesaria o contingente, determinadas o libres. Cfr. Alvira, Clavell \& Melendo (1986) pp. 211-212.
} 


\section{LÍMITES DEL FUNCIONAMIENTO DEL PRINCIPIO}

Si se cumplen todos los mencionados presupuestos (básicamente que exista una autoridad pública, una medida imperativa adoptada, un sujeto pasivo llamado a cumplirla, un criterio de razonabilidad jurídica y una posibilidad de control), entonces cabrá aplicar el principio de proporcionalidad. Sin embargo, sería ingenuo esperar que este principio nos proporcione todas las respuestas deseadas en el caso examinado.

El funcionamiento de este principio tiene sus límites internos y externos. El principio está limitado internamente porque hay casos que él no puede resolver. Además existen los límites externos que tornan inoperante al principio por causas ajenas a él. Los analizaremos en su orden.

\section{a) LÍMITES INTERNOS DEL PRINCIPIO}

El principio de proporcionalidad alemán presenta al menos tres tipos de límites a la hora de aplicarlo: 1 . adolece de los límites propios del conocimiento humano; 2 . no funciona en los casos de empate; y, 3. no opera cuando se sopesan valores inconmensurables. Veámoslos.

\section{Los límites del conocimiento humano}

Varios autores han destacado que los principios de proporcionalidad y ponderación tienen los mismos límites que tiene el conocimiento humano ${ }^{39}$. Por experiencia propia sabemos que nuestro conocimiento es limitado. Pensamos, reflexionamos, erramos, nos rectificamos. Hemos intentado asegurar el resultado de nuestro discurso racional formalizando procesos mentales que se muestran como "correctos", pero hasta los resultados mejor deducidos muchas veces nos hacen dudar. En el derecho se confió mucho -demasiado se piensa hoy- en la técnica del silogismo que todo juez debía aplicar, donde la premisa mayor era la norma, la premisa menor los hechos, y la conclusión la resolución de la sentencia. No descartamos que ese método haya servido para solucionar algún caso simple, pero ¡cuántos casos controvertidos y hasta sencillos se le escapan!

En este punto la hermenéutica jurídica tiene un paralelo con la historia del pensamiento griego. Fue justamente el Estagirita quien descubrió el silogismo, al que dedicó un excepcional análisis en el libro de los Analíticos. "El descubrimiento del silogismo entusiasmó a su autor. Quien hace un invento, y el silogismo lo inventa y lo estudia ampliamente Aristóteles, es natural que intente apurar su alcance. También es comprensible que sus seguidores centren su atención en ello y estudien menos las otras partes de sus planteamientos metodológicos" ${ }^{40}$. Pero suele olvidarse que Aristóteles era un pensador lo suficien-

\footnotetext{
39 Cfr. Elster (1999) pp. 11 y ss.; Bernal (2008) pp. 47-50; Portocarrero (2011) p. 129, quien ahí señala que si bien la ponderación "concede un alto grado de racionalidad, tiene también límites que le son intrínsecos. Los límites de la ponderación se derivan de los límites del conocimiento humano y la posibilidad de elaborar, a partir de lo que se puede llegar a conocer, juicios prácticos de deber ser". Bernal critica a "todo aquél que pretenda excluir de la ponderación las apreciaciones subjetivas del juez" porque incurriría en una "hiperracionalidad"BERNAL (2008) p. 49.

${ }^{40}$ Polo (2002) p. 141.
} 
temente abierto a la realidad como para percatarse de que no todos los campos admiten un mismo tipo de conocimiento. Jamás fue un panlogista que reducía todo a silogismos. Al contrario, se dio cuenta de que "la teoría del silogismo es la lógica del conocimiento de lo necesario. El silogismo es el método demostrativo riguroso. Se requieren dos condiciones para que funcione con entero rigor: que nosotros conozcamos lo necesario y que lo necesario exista (respectivamente, lógica formal y lógica material). En tal caso, se pueden conseguir conclusiones, en sentido estricto, es decir, se logra un razonar riguroso, demostrativo, aplicable a la ciencia teórica" ${ }^{\prime 1}$.

Aristóteles desarrolló su teoría del conocimiento no solo en los Analíticos, sino también en los Tópicos, la Retórica, la Poética y las Categorías. Un lugar central en la materia lo constituyen los "tópicos", que son los "lugares comunes" o "convicciones sociales compartidas" que, por lo mismo, no gozan de necesidad en sentido estricto. Ellos admiten la discusión, y se diferencian según el tipo de comunidad que los acepte. "¿Quién vence en una discusión? El que tiene mejores razones. En cambio, cuando se trata de lo necesario, la discusión carece de sentido. Lo necesario se puede enseñar, pero no se puede discutir" ${ }^{42}$. Polo concluye que "al distinguir estas dos dimensiones del hombre (su parecido con los dioses y su condición de animal social) tenemos las dos lógicas de Aristóteles. Por eso dice que cuando se trata de un saber práctico (acerca de lo útil, de lo justo, etc.) cuatro ojos ven más que dos. En cambio, cuando se trata de la ciencia rigurosa cuatro ojos no ven más que dos. El científico se puede aislar (...)"43.

Pero cuando en la discusión no hay "tópicos" (convicciones comunes), conviene aplicar la retórica. Por eso, para Aristóteles "la retórica tiene un uso fundamentalmente político y jurídico, en orden a resolver conflictos de intereses. Cuando hay conflictos de este tipo dentro de un grupo social sin convicciones comunes, se acude a la lógica para determinar un ganador. Cuando se trata de convencer sin partir de convicciones comunes, más que buenas razones, lo que hay son razones más o menos fuertes dirigidas, por ejemplo, a la emotividad. Por eso, al científico no hay que pedirle que sea persuasivo; al político, sí. Pero no se puede abandonar la actividad del pretor a la arbitrariedad. Hay que averiguar el tipo de lógica que utiliza” ${ }^{4}$.

El ímpetu progresista de la modernidad nos hechizó, haciéndonos pensar que el derecho podía operar como una ciencia exacta, donde el juez resolvería todo de manera mecánica. Hace unas décadas la jurismática pretendió hacernos creer algo semejante. Hoy somos más escépticos al respecto, y hasta le quitamos bastante crédito al elemental silogismo. En cambio, se pretende que los jueces apliquen cuasi-mecánicamente fórmulas como las siguientes, que sirven para fijar el peso de los elementos a ponderarse, deberían solucionar correctamente los conflictos:

\footnotetext{
41 Polo (2002) p. 142.

42 Polo (2002) p, 142

43 Polo (2002) p. 143.

44 Polo (2002) p. 144. La retórica no conduce a resultados de gran certeza. Polo considera que "eliminado el excesivo prestigio del silogismo, su uso lógico en la tópica es el más importante. Su uso retórico es más débil, porque el término medio del silogismo retórico es el menos universal (a la lógica retórica cabe llamarla lógica indicial; el término medio en ella no es más que un indicio)” Polo (2002) p. 146.
} 


$$
G i, j=I i-I j
$$

Fórmula diferencial

$$
\mathrm{GPi}, \mathrm{C} C=\frac{\mathrm{IPiC} \cdot \mathrm{GPiA} \cdot \mathrm{SPiC}}{\mathrm{WPjC} \cdot \mathrm{GPjA} \cdot \mathrm{SPjC}}
$$

Fórmula del peso completa

$$
G i, j=\frac{I i}{I j}
$$

Fórmula de cociente

$$
G i, j-n=\frac{I i \bullet G i \cdot S i}{I j \cdot G j \cdot S j+\ldots I n \bullet G n \cdot S n}
$$

Fórmula del peso extendida ${ }^{45}$

Para colmo de males, estas cuatro sencillas fórmulas propuestas por Alexy no han encontrado tanto consenso en la doctrina. Se han observado problemas, por ejemplo, en la acumulación de valores individuales y colectivos, en la conveniencia de una escala triádica, decimal o indefinida de pesos; en la serie (aritmética, geométrica o exponencial) con que los valores deben multiplicarse para apreciar bien el daño; en la forma de medir la certeza normativas y empíricas... Por eso los autores han propuesto nuevas fórmulas "más completas". Por citar a una entre muchos, Bernal ha propuesto "un modelo más completo de la fórmula del peso" ${ }^{46}$ como el siguiente:

$$
\mathrm{GPi}, \mathrm{jC}=\frac{(\mathrm{SiPiC} \cdot \mathrm{PJPiC}) \cdot(\mathrm{EPiC} \cdot \mathrm{VPiC} \cdot \mathrm{PPiC} \cdot \mathrm{APiC} \cdot \mathrm{DPiC}) \cdot \mathrm{GPiA} \cdot(\mathrm{SEIPiC} \cdot \mathrm{SNIPiC} \cdot \mathrm{SNPPiA})}{(\mathrm{SiPjC} \cdot \mathrm{PJPjC}) \cdot(\mathrm{EPjC} \cdot \mathrm{VPjC} \cdot \mathrm{PPjC} \cdot \mathrm{APjC} \cdot \mathrm{DPjC}) \cdot \mathrm{GPiA} \cdot(\mathrm{SEPPjC} \cdot \mathrm{SNPPjC} \cdot \mathrm{SNPPjA})}
$$

Aun así el mismo autor admite que no se le puede pedir tanta exactitud al principio de proporcionalidad, pues caeríamos en un "hiperracionalismo" ${ }^{47}$. Como dice Moreso, "aún en un modelo especificacionista, hay lugar para la indeterminación. No porque se produzcan empates en el sentido de Alexy, sino por las dos siguientes razones al menos: en primer lugar, como ya he recordado, por la vaguedad de los conceptos con los que representamos nuestras propiedades y, en segundo lugar, porque es posible imaginar supuestos en los cuales a partir de dos principios en conflicto se puedan generar dos o más reconstrucciones alternativas, las cuales, si bien resuelven de modo unívoco los casos paradigmáticos, representan diferencias significativas en otros casos y no hay, sin embargo, razones para elegir entre ellas" ${ }^{48}$. En el fondo hemos de preguntarnos, ¿hasta qué punto resulta admisible manejar aritméticamente variables cuantitativas mezclándolas con variables cualitativas,

45 Donde $P i$ representa el principio interventor que colisiona con el principio $P j . I P i$ la intensidad de la intervención; C alude al carácter concreto de $I P i$, que expresa las circunstancias del caso relevantes para la decisión. IPiC puede mostrar una intensidad $1, m o \mathrm{~g}$ (leve, mediana o grave), cuya variable también puede escribirse como "I $i$ " (luego, $I P i C=I i)$. A su vez, "Ij"alude a la intensidad hipotética del principio $P j$.

GPi es el peso abstracto de Pi. GPi también puede explicitarse con la variable $A$ (análoga a la variable $C$ ), de la que se obtiene GPiA que también se expresa sintéticamente con "Gi” (luego, GPiA=Gi). Distinta es la fórmula diferencial " $G i, j C$ " que resulta de $I i-I j$ y sirve para quienes trabajan con fórmulas aritméticas. " $G i, j$ ” resulta de Ii/Ij y sirve para quienes trabajan con fórmulas geométricas.

Para mayor precisión se ha adoptado la variable de la seguridad epistémica (seguro, plausible o falso) que se expresa con la variable "Si" para $P i$ y "Sj" para $P j$.

46 Bernal (2008) p. 67.

47 Bernal (2008) pp. 47-50.

48 Moreso (2008) p. 83. 
implícitas en un gran número de juicios de ponderación? Consideramos que prima facie, la presencia de variables cualitativas -más aún si ellas son discutidas- deberían eximir al juzgador de aplicar a rajatabla fórmulas como las enunciadas.

Probablemente bajo los esquemas aristotélicos, el principio de proporcionalidad no encajaría bien dentro de los Analíticos, sino dentro de los Tópicos si hubieren consensos o dentro de la Retórica si faltaren ${ }^{49}$. En cualquier caso, el uso de esta técnica no sería apodíctico, ni analizaría cuestiones con necesidad y debería dejar un espacio a la discusión. Para ver si una medida es proporcional o no, cuatro ojos valen más que dos, porque la cuestión suele presentar un amplio número de variables cuantitativas y cualitativas que tornan muy compleja la resolución. Ello abona para que se limite a los jueces el uso de la proporcionalidad a los casos estrictamente necesarios. En general, un parlamento con cientos de ojos debería apreciar de mejor modo la razonabilidad de una medida que el mero par de ojos de un juez.

De la intuición aristotélica sacamos en claro dos directrices: (i) será más seguro usar el principio de proporcionalidad cuando existan "tópicos", consensos sociales, sobre los elementos en juego, que cuando falten; y, (ii) las decisiones adoptadas por grandes cuerpos colegidos, con decenas de ojos, serán menos propensas a ser examinadas por los limitados ojos del juzgador.

\section{Los casos de empate valorativo}

Los casos de empate valorativo son muy raros en el derecho, pero se dan. El empate se da cuando, a la hora de ponderar distintos extremos, aparece que todos poseen igual valor. Según el subprincipio de proporcionalidad estricta, debe darse un equilibrio entre la restricción constitucional y la satisfacción del fin buscado. Aplicando la sencilla escala triádica (alta, media, baja), clasificamos la restricción en función de su intensidad y la satisfacción en función de su importancia. Según la doctrina tradicional, se reputan desproporcionadas las medidas con alta-restricción de derechos que buscan una satisfacción-media o satisfacción-baja. A la vez, parecen proporcionadas aquellas medidas que busquen una satisfacción-alta, con una restricción-baja (y generalmente con una satisfacción-media). Habría empate en aquellas medidas donde tanto la satisfacción como la restricción son altas, medias, o bajas ${ }^{50}$. Si la balanza no se inclina por nadie, ¡a quién ha de darse la razón? La respuesta más común indica que el empate se resuelve a favor del legislador: su norma quedará en pie $^{51}$.

En realidad, los autores no se quedan contentos con el empate y, lejos de lanzar una moneda al aire para decidir suertes, procuran poner algún peso adicional en el platillo del

\footnotetext{
${ }^{49}$ Justamente se ha señalado que la ponderación no es más que una "fórmula retórica" o "una técnica de poder”. Leisner (1997b) p. 171. Quizá se excede al declarar que carece de un concepto claro y de una estructura jurídica precisa.

50 Existen otras posibilidades no analizadas, que además se podrían multiplicar si sustituimos la escala triádica por otra con más variables numéricas (v. gr. del 1 al 10) o, ni se diga, si además introducimos variables cualitativas. No nos interesa ahora mostrar cuan complejo puede convertirse el asunto. Solo deseamos delinear el concepto de "empate valorativo".

51 Véanse Bernal (2008) pp. 57-58; Lopera (2008) p. 294; Moreso (2008) p. 72, quien desarrollando el criterio de Alexy concluye que "las restricciones legislativas al ejercicio de un derecho fundamental están justificadas".
} 
legislativo para que la balanza se incline a su favor. En concreto, sacan a la luz argumentos como el de la presunción de constitucionalidad de las leyes, el control constitucional como ultima ratio, la división de poderes propia del Estado constitucional y el favor de la democracia $^{52}$. Como se ve, los pesos que se ponen platillo del legislador no tienen nada que ver con el nivel de satisfacción y restricción que la medida causa, porque si nos ciñéramos a ellos no habría forma de resolver el asunto. Se evidencia, pues, que el principio de proporcionalidad no opera en los casos de empate valorativo ${ }^{53}$, de tal manera que se hace necesario recurrir a argumentos externos al principio para llegar a una solución. A la vez el recurso a estas externalidades demuestra una verdad de Perogrullo: ni la ponderación, ni la proporcionalidad son el único método de resolver conflictos.

Por lo demás, no consideramos que el empate deba resolverse siempre a favor la autoridad que dicta la medida. Piénsese, por ejemplo, en una administración tributaria que mediante impuestos quita $\$ 100$ a unos ricos para darle $\$ 100$ a otros ricos: el nivel de satisfacción de unos es exactamente igual al nivel de restricción de otros, pero parece que tan absurda medida no debería mantenerse. Y, desde luego, el empate jamás debería justificar al legislador que violenta el núcleo esencial de los derechos fundamentales, por el principio de intangibilidad de estos derechos, por el principio pro homine, por el principio pro libertate... y por muchos otros principios que huelga aquí considerar ${ }^{54}$.

\section{La inconmensurabilidad}

Una de las críticas más frecuentes a los principios de ponderación y proporcionalidad es la imposibilidad de comparar extremos cualitativamente diversos: la satisfacción de un fin y la restricción del derecho. Sería comparar manzanas con naranjas ${ }^{55}$. En la jurisprudencia norteamericana, el juez Scalia ha manifestado que este proceso de argumentación implica realizar una comparación de dos magnitudes inconmensurables: sería como determinar "si una línea es más larga que lo que una determinada piedra es más pesada" 56 . Se suma a la crítica Aleinikoff, quien considera que no existe un criterio racional objetivo para valorar o comparar cada interés en juego, ni menos un tertium comparationis que haga las veces de aquella moneda común necesaria para evaluar los extremos comparados. Según el autor, "ningún sistema de identificación, evaluación y comparación de intereses ha sido desarrollado" 57 . Por ello concluye que "la teoría de la interpretación que fue creada para

\footnotetext{
52 Así, en el Epílogo a la Teoría de los derechos fundamentales (2002, p. 43), Alexy defiende una carga de argumentación a favor de la ley, que se ha de tener como "no desproporcionada". Bernal se inclina "a favor de la democracia” (2008, p. 58). Ante la duda de la validez, se considera que debe mantenerse lo que los representantes del pueblo han decidido.

53 En palabras de Alexy, "los casos de empate se sitúan en un margen de acción para la ponderación, y, por lo tanto, en un margen de acción estructural para la ponderación” AlEXY (2008) p. 29.

54 En apoyo de esta postura encontramos una opinión del mismo Alexy, vertida quince años antes de mantener lo manifestado a nota 42. En su Teoría de los derechos fundamentales Alexy (1997) p. 549, Alexy justifica una carga de argumentación a favor de la libertad y la igualdad jurídica, basada en el principio in dubio pro libertate.

55 Sobre este ejemplo, cfr. Borowski (2013) pp. 1409-1418.

56 Cfr. Bendix Autolite Corp. vs. Midwesco Enterprises, Inc., 486 U.S. 888, 897(1988).

57 Aleinikoff (1987) p. 982.
} 
traer al realismo al derecho y limitar la subjetividad en la interpretación constitucional parece ser cada vez más manipulativa" ${ }^{58}$.

Aleinikoff lleva su parte de razón. En efecto, la operación intelectual de comparar exige al menos tres cosas: 1. que existan dos o más elementos distintos; 2. que tales elementos puedan mesurarse; y, 3. que la medida con la que se los mesura sea la misma. Respecto al primer punto, en el principio de proporcionalidad existen dos extremos claramente distintos: la satisfacción y la restricción ocasionadas por la medida ${ }^{59}$. Respecto al segundo punto, hay que matizar un poco las críticas. Observamos que con frecuencia los elementos son absolutamente mesurables (v. gr. cuando está en juego la propiedad de un inmueble con un valor catastral prefijado, o cuando se evalúan los costos de una política económica); otras veces no, pero pueden tenerse como elementos de "altísimo valor" (v. gr. la vida humana) o por el contrario de "ínfimo valor" (v. gr. un rato de ocio); finalmente habrá elementos extremadamente difíciles de conmensurar (v. gr. la libertad de conciencia). Será tortuoso aplicar el principio de proporcionalidad a aquellos elementos difícilmente mensurables, así como ponderar dos elementos que sean a la vez de altísimo o de ínfimo valor ${ }^{60}$. Quizá lo más honesto en tales casos será que el juez reconozca expresamente que ahí es riesgoso aplicar el principio de proporcionalidad.

Finalmente, respecto a la medida de comparación (el tertitum comparationis) se ha afirmado que el punto de referencia siempre debe de ser la constitución, y los fines, valores, principios, intereses, derechos, pretensiones, etc. consagrados en ella ${ }^{61}$. Sin embargo, la historia ha demostrado que no siempre la jurisprudencia se ha limitado a analizar presupuestos constitucionales ${ }^{62}$.

Introducimos aquí una consideración netamente metafísica que puede arrojar algo de luz. Ontológicamente existe un término común a todo lo que existe en este universo, y esto es el ser. El ser se "tiene" o es "participado" en diferente grado ${ }^{63}$. A mayor intensidad del ser, mayor perfección ontológica, mayor valor metafísico. Existen diversos géneros de

\footnotetext{
58 Ibid., p. 981. La literatura sobre la crítica la inconmensurabilidad es abundante. Cfr. HABERMAS (1996) p. 369; Raz (2001) p. 46; Günther (1988) pp. 275 y ss.; Tribe (1985) p. 595; Henkin (1978) p. 1048; FrantZ (1963) p. 748; Hirschberg (1981) pp. 132-135, 153 y ss.; JanSEN (1997) p. 152. Finnis (1997) pp. 219 y ss. apunta que la conmensurabilidad solo es posible si: (i) los objetivos se hallan bien definidos, (ii) los costos pueden compararse con el parámetro de una única unidad de valor, (iii) los beneficios pueden ser cuantificados con esa medida común, y, (iv) los costos y beneficios no comparables no deben estimarse de relevancia.

59 En la ponderación simple pueden existir una multitud de elementos en los diferentes platillos de la balanza: principios, derechos, intereses, expectativas, pretensiones, etc.

${ }^{60}$ Probablemente en este caso lo mejor sea declarar que existe un presunto empate valorativo.

${ }^{61}$ En este sentido, Portocarrero (2011) p. 82.

${ }^{62}$ La Corte Suprema de Estados Unidos no solo ha recurrido al paradigma de la constitución, sino también a criterios históricos, al consenso social vigente o a la importancia en abstracto de un determinado interés. En Schneider vs. State 308 U.S. 147 (1939), por ejemplo, la Corte Suprema pondera intereses que están fuera de la Constitución.

63 Una vertiente metafísica muy importante, entroncada en Tomás de Aquino, defiende los grados del ser mediante la noción de participación y analogía del ser. Otra visión distinta tienen filósofos como Leonardo Polo, que no aceptando la participación del ser, sí admiten en cambio la diversidad de perfecciones.
} 
ser: el acto de $\operatorname{ser}^{64}$, la forma sustancial, los accidentes, los hábitos y las acciones (o actos segundos $)^{65}$. En principio los primeros valen más que los últimos, a menos que las potencialidades confieran una elevación del $\operatorname{ser}^{66}$. Lo jurídico se relaciona siempre de manera más o menos directa con algún tipo de ser, y en esa medida posee valor. Con lo cual, no es tan cierto que entre los diversos elementos a ponderarse (v. gr. fines, valores, principios, intereses, derechos, pretensiones, etc.) no exista nada en común. Traducido al lenguaje popular, a nadie escapa que la vida humana (y el derecho a tenerla) vale más que la vida de una mosca (y que el derecho al medio ambiente), ni que diez gramos de oro valgan más que un solo gramo; ni que en una invasiva operación quirúrgica pese más el interés jurídico por salvar un órgano que por mantener la piel sin cicatrices... Es necesario determinar ontológicamente qué valor pesa más y qué valor pesa menos. Sin una sólida escala de valores, si todo fuera relativo, a la final sería imposible realizar el más modesto balanceo. No desarrollamos más esta idea que ameritaría muchas consideraciones y líneas adicionales ${ }^{67}$.

\section{b) LÍMITES EXTERNOS DEL PRINCIPIO}

Para que la proporcionalidad funcione adecuadamente son necesarios al menos dos elementos externos al principio, que no siempre se dan: 1. que exista un juzgador razonable; y, 2. que exista certeza en las premisas y elementos del principio.

\section{La razonabilidad del juzgador}

Se le acusa al principio de proporcionalidad de ser una estructura formal vacía, basada exclusivamente en las apreciaciones subjetivas, ideológicas y empíricas del juez, quien se encontraría autorizado para poner a discreción tales apreciaciones en los diferentes platillos de la balanza y así decidir arbitrariamente el caso ${ }^{68}$. En fin, sería una figura retórica para justificar las apreciaciones del juez ${ }^{69}$. En el extremo, Habermas ha sostenido directamente

${ }^{64}$ A la vez, existen tres tipos de actos de ser: el divino, el del resto de personas y el del universo, cuya perfección varía en ese orden. Polo pone en el acto de ser personal los trascendentales antropológicos de la libertad y la coexistencia, lo que resulta muy relevante a la hora de establecer la jerarquía axiológica.

65 El significado de ser no es unívoco, sino que se aplica a diversas realidades con una cierta analogía. En primer lugar, al acto de ser, al ser sin más, al constitutivo más radical de todo por el cual las cosas "son". En segundo lugar, el ser se predica del modo de ser, que puede ser: substancial, accidental, formal, corporal, intencional, etc. El mar tiene un "modo de ser" muy distinto al de un perro, pero ambos coinciden en que "son". Cfr. GARCía López (1995) pp. 43-52.

66 La jerarquía axiológica amerita explicarse en un estudio aparte. En breve, según los criterios dados deducimos el siguiente orden de valores: el divino, el humano y el del cosmos. Dentro de lo humano distinguimos la dignidad de la persona (propia de su acto de ser) y sus valores relacionados (libertad, sociabilidad, etc.), los propios de su espíritu (verdad, bien y belleza), los de su corporalidad (v. gr. vida material, salud, integridad física, etc.), de sus hábitos buenos (virtudes intelectuales y corporales) y acciones meritorias. Luego tocaría sopesar el valor de cada ente del cosmos, ordenándolo según su perfección ontológica (v. gr. animales, plantas, materia inerte, etc.).

67 Entre otras cosas, habría que explicar por qué la tesis de los derechos de distinto valor no se contrapone a las teorías no conflictivistas o "concertistas" de los derechos, ni presupone una minusvaloración de los titulares del derecho diverso.

68 En este sentido, Ossenbühl (1995) p. 905; Betterman (1964) pp. 601 y ss.; García Amado (1996/1997) p. 71.

69 Cfr. De Lora (2000) pp. 359-369; García Amado (1996/1997) pp. 65-86; GaSt (2006) p. 382. 
la irracionalidad y peligrosidad de la ponderación, por estar desprovista de criterios que garanticen la objetividad decisional ${ }^{70}$, a lo cual Schlink ha añadido que la ponderación resulta innecesaria y que su uso puede omitirse dentro del principio de proporcionalidad ${ }^{71}$.

En defensa del principio se observa que tales críticas no van directamente contra el principio, sino contra los jueces que utilizan el principio ${ }^{72}$. Lo irracional no es el principio, sino el juzgador que lo aplica mal. Una sentencia razonable requiere la presencia de un juez razonable. Y lo dicho vale para la aplicación de cualquier técnica en el derecho: desde la subsunción ${ }^{73}$, hasta la ponderación y la proporcionalidad. Al final del camino la decisión judicial siempre quedará en manos de un juez con convicciones propias.

De fondo está que si bien la más depurada técnica jurídica puede corregir ciertos desatinos lógicos, ella no servirá de nada si la dejamos en manos del juez inicuo que solo medita en cómo justificar su posición. El juez con una vida sexual desatada se inclinará por una sentencia más laxa cuando decida sobre el estándar de obscenidad o indecencia de una publicidad. Pensamos lo que obramos, obramos como pensamos ${ }^{74}$. Por eso, para evitar desatinos e injusticias, una sentencia justa requiere tanto la presencia de un juez técnico, como la de un juez justo.

Dicho lo anterior, vale ahora hacer algunas precisiones. En realidad, no toda decisión requiere del mismo grado de finura en el tanteo de los extremos. Una multa de tránsito la impone con justicia el policía más ignorante viendo el hecho y aplicando la ley, y lo mismo el guardacostas que lícitamente impide traspasar la línea de frontera a quien no muestra los documentos debidos. El problema con el principio de proporcionalidad es que maneja fórmulas más complejas, que evalúa una multitud de variables cuantitativas y cualitativas, a lo que se suma la mal definida línea entre lo "políticamente razonable” y lo "jurídicamente razonable” (que es lo único sobre lo que el juez podría fallar), todo lo cual termina dando mayor peso a las convicciones del juez.

Un juez razonable ha de ser lo suficientemente honesto como para admitir sus propios límites a la hora de juzgar.

\footnotetext{
70 Habermas (2008).

71 Ver lo dicho a nota 13.

72 Confrontar con Portocarrero (2011).

73 Como manifiesta Serna, "aun admitiendo la viabilidad del modelo silogístico de la subsunción como forma lógica de la aplicación del derecho, hay al menos tres operaciones que no pueden llevarse a cabo sin el concurso personal -creativo, valorativo- del intérprete, y no se obtiene, por tanto, como fruto de una tarea subsuntiva o lógico-deductiva, sino mediante una elección que ha de ser objeto de una elección ad hoc: a) la selección de la norma aplicable (...) b) La equiparación entre supuesto de hecho de la norma, que es siempre general y abstracto, y los hechos del caso (...). c) La determinación de la consecuencia jurídica” Serna (2002) pp. 746 y ss.

74 Cfr. Cardona (1973). En principio, las conclusiones del intelecto escapan al poder de la voluntad y se le imponen. Que 2+2=4 no depende de que nadie lo quiera; serán 4 en cualquier época o sociedad. Lo mismo con las primeras conclusiones de la ciencia moral y con los primeros principios del derecho. In recto no son disponibles. Sin embargo, in oblicuo -máxime en las ciencias humanas- quien actúa mal tiende a justificarse y esa justificación le lleva a desatender las razones que pesan sobre su conciencia y a fijarse más en lo que alaga o excusa. Si no hay esfuerzo por corregir la mala conducta, a la larga la voluntad termina jugándole una mala pasada al intelecto, y el sujeto termina optando por una posición intelectual más cómoda, por un juicio de conciencia menos exigente.
} 


\section{La certeza de las premisas y elementos del principio}

Hemos visto que están llamados a aplicar el principio de proporcionalidad tanto la autoridad pública, como el juzgador. Comencemos hablando del legislador que sanciona una ley muy restrictiva de los derechos. En una célebre frase, Alexy señaló que "cuanto mayor sea una intervención en un derecho fundamental, tanto mayor deberá ser la certeza de las premisas que fundamentan la intervención" 75 . Dicho lo mismo en negativo: la falta de certeza restringe la posibilidad de intervenir derechos fundamentales, reduciendo el margen de discrecionalidad de la autoridad. Por un elemental sentido común, son desproporcionadas las restricciones graves a los derechos hechas por el legislador basándose en rumores, en alarmas no probadas, en raros supuestos o en riesgos muy poco probables. Una ley que procura evitar una peste no probada, ni probable, mediante expropiaciones, restricciones de acceso a predios, silenciando además la opinión contraria, sería irrazonable y la justicia constitucional debería dejarla sin efectos.

Caso distinto es cuando es el juzgador quien no ha logrado certezas en las premisas y elementos que resultan necesarios para que funcione adecuadamente el principio de proporcionalidad. Si el punto de partida es incierto, más incierto aún será el resultado. Si el juez introduce premisas irracionales o falsas en su argumentación, será imposible que obtenga resultados ciertos. Por tanto, como en este caso el principio de proporcionalidad no opera (o lo hace produciendo disfunciones), aquí sí cabe concluir que el juez no está avalado para dejar sin efecto la norma sub iudice, creándose un "margen de acción epistémico normativo" 76 a favor del Parlamento y de los poderes públicos sobre los cuales el Poder Judicial no puede intervenir.

En ambos casos, las incertezas pueden cernirse sobre ${ }^{77}$ :

- El fin de la norma: cuál es la finalidad de la norma y su alcance, si tiene cobijo constitucional o no, si es lícito, si es un fin único o son varios fines, si tal fin implica una satisfacción alta, media o baja, etc.

- La medida adoptada: si es lícita en sí misma o no, si es idónea para alcanzar el mencionado fin, si existen pruebas suficientes que respalden su eficacia; cuáles y cuántas podrían ser las medidas alternativas; dentro de las medidas posibles, cuál es la menos restrictiva, cuál es la más satisfactoria y cuál es la que mejor logra el equilibrio, etc.

- Las restricciones y satisfacciones: si existen o no, si son derechos, meras expectativas, intereses, etc.; si su nivel es intenso o importante; si se está disponiendo de derechos intangibles, etc.

- La proporcionalidad en sentido estricto: cuál es el tertium comparationis, si es proporcional o no, si la medida es "jurídicamente razonable" o "políticamente razonable”, etc.

\footnotetext{
75 Alexy (2008) p. 38.

76 Alexy (2002) p. 58.

77 En general, siguiendo a Alexy se dice que la incerteza se puede dar tanto en las premisas empíricas, como en las normativas. Con frecuencia el análisis se limita a la certeza del grado de idoneidad, del grado de lesividad y de la necesidad (v. gr. Lopera (2008) pp. 82-83), descuidando otros aspectos importantes de la certidumbre. Hemos procurado aquí integrar estos aportes en un análisis de la certeza más completo.
} 
A la vez, los grados de certidumbre pueden $\operatorname{ser}^{78}: 1$. La certeza, que es "el estado de la mente que se adhiere firmemente y sin ningún temor a la verdad"79. Ella admite principalmente dos grados: la "certeza absoluta", que excluye absolutamente toda duda sobre la tesis contraria, y la "certeza moral" que solo excluye las dudas razonables que apoyen la tesis contraria (aunque deje un resquicio para la posibilidad del error) ${ }^{80}$. La mejor doctrina canónica afirma que basta la certeza moral para dictar sentencia ${ }^{81}$. La probabilidad no es un estado de la mente, y solo constituye un indicio sobre la respuesta correcta. Un juez no puede basarse en probabilidades para condenar a nadie, ni para derogar ninguna ley, sino en razones de fondo y en pruebas que ofrezcan al menos una certeza moral.

Además existen otros estados mentales de certidumbre. 2. La duda, que "es el estado en el que el intelecto fluctúa entre la afirmación y la negación de una determinada proposición, sin inclinarse más a un extremo de la alternativa que al otro" ${ }^{22}$. 3. La opinión, que implica el asentimiento a la verdad de una parte de la contradicción, con temor de la verdad de la opuesta ${ }^{83}$. 4. La fe, donde "la voluntad mueve al entendimiento a asentir con certeza, sin miedo a que sea verdad la opinión contraria, basándose en el testimonio y la autoridad de otro" ${ }^{84}$. 5. El error, que consiste en afirmar lo falso como verdadero ${ }^{85}$. La duda, la opinión, la fe y el error no son estados mentales idóneos para que los jueces constitucionales dicten ningún tipo de sentencia.

El nivel de certeza amplía o reduce el ámbito de control de proporcionalidad que tienen los jueces. Según Ávila, los jueces podrán controlar menos las decisiones de autoridad pública "cuanto más: (1) dudoso sea el efecto futuro de la ley; (2) difícil y técnico sea el juicio exigido para el tratamiento de la materia; (3) abierta sea la prerrogativa de ponderación que la Constitución atribuye al Poder Legislativo" ${ }^{86}$. En cambio, los jueces podrán ejercer un mayor control, "cuanto mayor sea: (1) la condición para que el Poder Judicial construya un juicio seguro al respecto de la materia tratada por el Poder Legislativo; (2) la evidencia de la equivocación en la premisa elegida por el Poder Legislativo como justificación para la

\footnotetext{
78 Criticamos aquí la escala triádica de certidumbre (que la encasilla en cierta, plausible y falsa) adoptada por muchísimos doctrinarios, que no toma en cuenta - probablemente desconoce- la gnoseología más básica y clásica. No se trata de una mera cuestión doctrinal filosófica, sino que tiene serias repercusiones en el derecho probatorio y en otras ramas. Una exposición adecuada para el público general puede encontrarse en LlaNo (1984) pp. 51-70.

79 LLANO (1984) p. 52.

${ }^{80}$ Aristóteles advertía que "no debemos buscar el mismo grado de certeza en todas las cosas" (Ética a Nicómaco, I, 1094b 13) y Tomás de Aquino precisaba que "en los negocios humanos no puede darse una prueba demostrativa e infalible; basta una certeza moral” (Suma Teológica, I-II, q. 105, a 2, ad 8).

81 La doctrina más clara que hemos encontrado al respecto consta en el Magisterio Pontificio. "In opposizione a questo supremo grado di certezza il linguaggio comune chiama non di rado certa una cognizione che, strettamente parlando, non merita un tale appellativo, ma deve qualificarsi come una maggiore o minore probabilità, perché non esclude ogni ragionevole dubbio e lascia sussistere un fondato timore di errare. Questa probabilità o quasi-certezza non offre una base sufficiente per una sentenza giudiziaria intorno alla obbiettiva verità del fatto" (Pío XII, Discurso a la Rota Romana de 1-X-1942). Cfr. JuAn PABLo II, Discurso a la Rota Romana de 4-II-1980.

82 Llano (1984) p. 58.

83 Cfr. Llano (1984) p. 61; Tomás de Aquino, De veritate, q. 14, a. 1.

${ }^{84}$ LLANO (1984) p. 63.

85 Se distingue de la ignorancia o nesciencia, que es la simple ausencia de conocimiento.

86 Ávila (2011) p. 157.
} 
limitación del derecho fundamental; (3) la restricción del bien jurídico constitucionalmente protegido, que se contrastará por su carácter fundamentador o función de soporte de otros bienes (por ejemplo, vida e igualdad) y por la jerarquía sintáctica en el ordenamiento constitucional (por ejemplo, principios fundamentales)" ${ }^{87}$.

Los casos de duda sobre la constitucionalidad de las normas han de resolverse como los casos de empate valorativo: acudiendo a otros principios y razonamientos extrínsecos a la proporcionalidad. Cuando las restricciones fueren menores prevalecerá la presunción de constitucionalidad de los actos de las autoridades o el principio de declaración de inconstitucionalidad como última ratio ${ }^{88}$, mientras en los demás casos tenderá a prevalecer el principio pro homine, pro libertate, pro informatione, etc.

\section{LÍMITES DE LA EFICACIA DEL PRINCIPIO}

Si se cumplen todos los presupuestos de aplicación del principio de proporcionalidad, y este funciona correctamente (porque no se han presentado límites funcionales internos o externos), arrojará un resultado cierto sobre la proporcionalidad de la norma en abstracto, pero no necesariamente afectará a todos los casos concretos sobre los que eventualmente podría caer. La eficacia del principio tiene al menos dos límites: a) los derechos adquiridos que no se podrán desconocer; y, b) la aparición de casos futuros más complejos, sobre los que el juicio de proporcionalidad no operará. Los veremos a continuación.

\section{A) LOS DERECHOS ADQUIRIDOS}

Como vimos ut supra, el principio de proporcionalidad nació para controlar los excesos de poder que perjudicaban los derechos del ciudadano. Sin embargo, no siempre se ha conseguido este objetivo. Como dice Covarrubias, paradójicamente "la actual estructura del test contribuye a que los derechos queden en buena medida sujetos a un cálculo donde muchas veces prevalece la supuesta primacía de los objetivos estatales que legítimamente se pretenden alcanzar a costa del sacrificio de los derechos fundamentales" ${ }^{89}$. Esto nos mueve a reafirmar que la aplicación de la proporcionalidad debe hacerse pro homine, a favor de los derechos de las personas, y que la sentencia que aplique la proporcionalidad debe procurar sanar toda vulneración de derechos que ocasione su aplicación.

Con frecuencia las medidas adoptadas por la autoridad pública pesan sobre varios derechos adquiridos de los ciudadanos. Un ejemplo bastante típico, sometido en muchísimos países al control de proporcionalidad, son las expropiaciones múltiples que las autoridades realizan para trazar vías en media ciudad. Si bien estas fuertes medidas suelen ser razonables (el alto grado de satisfacción compensa muchas penas), no so capa de la proporcionalidad se podrán desconocer los derechos adquiridos de los ciudadanos sobre sus predios. Naturalmente, la administración tendrá el deber de indemnizarles.

\footnotetext{
87 Ávila (2011) p. 156.

88 En este sentido, por ejemplo, Cianciardo (2009a) p. 93.

89 Covarrubias (2012) p. 453.
} 
Algo semejante sucede en la contratación pública con el ius variandi, cuando en aras del interés público el Estado decide unilateralmente cambiar las condiciones del contrato, ocasionando un perjuicio a la parte privada que ve desmejorada su posición contractual. Y un efecto semejante ocurre con el factum principis, que indirectamente trastoca las condiciones contractuales ${ }^{90}$. En uno y otro caso la doctrina y la jurisprudencia comparada coinciden en que el Estado mantiene el deber de respetar el equilibrio económico del contrato y los derechos pactados, compensando con nuevos ajustes contractuales o directamente indemnizando in integrum ${ }^{91}$.

En rigor, una norma que conculque derechos adquiridos sin indemnizarlos nunca será razonable. Tal decisión sería más bien la arbitrariedad de un tirano a quien no le importa pisotear cabezas y, por lo mismo, debería invalidarse. Pero como el análisis de proporcionalidad lo suele hacer el juez en abstracto, sin considerar todos los posibles perjuicios -máxime en el caso del factum principis-, entonces conviene señalar que la norma reputada "proporcional" tiene un límite: no puede desconocer los derechos adquiridos, ni las condiciones contractuales establecidas a favor del contratista en los contratos públicos.

\section{B) Los CASOs Futuros}

Un sector de la doctrina ha criticado los principios de ponderación y proporcionalidad por su "particularismo"92, es decir, por siempre requerir un análisis ad hoc que atienda las circunstancias concretas de cada caso y a los intereses envueltos en cada ocasión ${ }^{93}$. Esto dificultaría, y hasta imposibilitaría, producir criterios generales aplicables a nuevas situaciones. Así, no sería factible generar líneas jurisprudenciales, y se terminaría sacrificando la certeza del derecho, la coherencia del sistema y la igualdad ante la ley.

A la vez existe otro sector que, dándole a esta técnica formal la validez de todo principio, sí considera que la proporcionalidad es capaz de producir reglas generales para el ordenamiento jurídico ${ }^{94}$. Sus defensores suelen observar que toda aplicación de reglas o principios comprende un cierto margen de incertidumbre o de "derrotabilidad", por usar

90 La institución designa aquella acción de la administración, adoptada con carácter general, que indirectamente produce una alteración de la relación contractual perfeccionada entre el contratista y la administración. Cfr. JÉze (1950) pp. 36 y ss.; Mestre (1985).

91 El Tribunal Supremo español ha reconocido en múltiples fallos el "deber de la Administración de compensar al contratista de los perjuicios que la modificación le cause, a fin de mantener el equilibrio económico (...)” (sentencia de 2-VI-1979; T. Ar. 2866). Además ha precisado que "si el "poder de variar" ha sido justamente equiparado a la potestad expropiatoria, y esta exige la restitución o pago integral, es este el criterio que ha de observarse aquel so pena de conculcar esa restitutio in integrum y el equilibrio económico del contrato, habiendo enlazado este TS la potestas variandi con el derecho del contratista o del concesionario a la compensación real y verdadera de todos los daños y de todos los perjuicios que sean consecuencia de la modificación impuesta por la Administración. Sentencias de 12-III-1913 y 20-II-1956 (R. 1029), entre otras, completadas con las de 30 de noviembre de 1970 (R. 4922) y 18 de diciembre de 1981 (R. 4811)” (sentencia de 20-XII-1983, R. Ar. 6843).

92 V. gr. Celano (2002); Moreso (2003), quien intenta superar este "particularismo" mediante un nuevo modelo de ponderación.

93 Cfr. Aleinikoff (1987) p. 981; Bethge (1977) p. 276; Schneider (1979) p. 23.

94 Es interesante la crítica que Atienza formula contra uno de los que impugnan el "particularismo". "Moreso defiende una estrategia especificacionista para la ponderación, que sería capaz de superar el particularismo. Sin embargo, de lo que no parece darse cuenta Moreso es de que, en realidad, él está diciendo lo mismo que Alexy; 
un término hartiano ${ }^{95}$. En realidad todo análisis jurídico, incluido el silogístico ${ }^{96}$, requiere del concurso de una inteligencia que ad casum investigue cuáles son los hechos, qué normas se adecuan al caso, qué resultados es posible extraer, etc.

Sea cual fuere la postura, parece claro que la ratio extraída de la aplicación ad hoc del principio, no aplica a los casos futuros cuando: (i) no se cumplan con exactitud los presupuestos del caso previo; (ii) el nuevo caso presente más variables a tomarse en cuenta; $y$, (iii) haya existido incertidumbre en la aplicación del principio de proporcionalidad en el caso previo. Sería una magna insensatez tomar como regla general aquella solución a la que un juez llegó aplicando el principio de proporcionalidad en un caso sumamente controvertido, lleno de incertidumbre en las premisas del principio, en su funcionamiento y en sus conclusiones.

\section{BALANCE FINAL}

Del análisis efectuado extraemos las siguientes conclusiones:

1. Ni la jurisprudencia, ni la doctrina han llegado todavía a un consenso sobre la noción definitiva y los contenidos del principio de proporcionalidad.

2. El principio de proporcionalidad diseñado por la jurisprudencia alemana tiene tres tipos de límites: a) los límites a priori, que son los presupuestos del principio, sin los cuales no cabe aplicarlo; b) los límites del funcionamiento, que ocasionan disfunciones o tornan inoperante al principio; y, c) los límites a posteriori que causan una inaplicabilidad parcial del principio a ciertos casos.

3. Para que el principio de proporcionalidad pueda aplicarse, deben darse los siguientes presupuestos: que exista una autoridad pública, una medida imperativa adoptada, un sujeto pasivo que deba cumplirla, un criterio de razonabilidad jurídica, y una posibilidad de control. Jamás es admisible que un juez revise la razonabilidad política de las decisiones. Tampoco cabe aplicar el principio a las relaciones jurídicas de coordinación, ni a las decisiones de autoridad privada; para el efecto, sería necesario reestructurar la arquitectura del principio. Además, resulta superfluo aplicar el principio a los casos de salida única.

4. Al usar el principio de proporcionalidad pueden aparecer varios límites internos y externos a su funcionamiento. En tales casos, la prudencia aconseja una aplicación restrictiva del principio.

5. Respecto a los límites internos hay que decir que el principio no funciona en los casos de empate valorativo, ni cuando existen valores extremadamente difíciles de mesurar. En cambio, sí funciona, pero con disfunciones y resultados inciertos cuando: (i) no existen "tópicos", convicciones sociales comunes, sobre las cuales basar la resolución; (ii) el asunto presenta un gran número de variables, más aún si estas son

o, si se quiere, Moreso está olvidando lo que antes señalaba: que la ponderación genera una regla general y abstracta y, por eso, no es ad hoc, en el sentido en el que él usa esta expresión”. Atienza (2010) p. 8.

95 Cfr. Hart (1950) pp. 145-166.

96 Vid. la opinión de Serna expresada a nota 59. 
discutibles o de orden cualitativo; y, (iii) se sopesan fines, satisfacciones o restricciones difíciles de mensurar.

Por razones gnoseológicas, conviene limitar el control judicial de la proporcionalidad de aquellas normas adoptadas por los grandes cuerpos colegiales. En materia de razonabilidad, no conviene que dos, seis o diez ojos juzguen la razonabilidad de lo visto por cientos de ojos.

Las fórmulas matemáticas creadas para valorar la proporcionalidad de la medida solo funcionan adecuadamente en los casos simples que manejen principalmente variables cuantitativas. Prima facie, la presencia de variables cualitativas -y más aún si ellas son discutidas- debería eximir al juzgador de aplicar a rajatabla este tipo de fórmulas.

7. Respecto a los límites externos, se observa que el principio de razonabilidad solo funciona cuando lo aplican jueces razonables, probos y técnicos. Se precisa una especial honestidad intelectual del juez, capaz de admitir las propias limitaciones. Además, la incerteza del juzgador sobre las premisas del principio o sobre cualquiera de sus elementos (v. gr. sobre el fin, la medida, los derechos lesionados o la misma proporcionalidad) limita el grado de intervención al cual está legitimado el juez.

Los casos de duda sobre la constitucionalidad de las normas han de resolverse como los casos de empate valorativo: acudiendo a criterios extrínsecos a la proporcionalidad. Cuando las restricciones fueren menores prevalecerá la presunción de constitucionalidad de los actos de las autoridades o el principio de declaración de inconstitucionalidad como última ratio, mientras en los demás casos tenderá a prevalecer el principio pro homine, pro libertate, pro informatione, etc.

8. En cuanto a los límites a posteriori del principio de proporcionalidad, este no cabe aplicarlo desconociendo los derechos adquiridos de los ciudadanos. Tampoco aplica a los casos futuros cuando: 1. no se cumplan con exactitud los presupuestos del caso previo; 2. el nuevo caso presente más variables a tomarse en cuenta; y, 3. haya existido incertidumbre en la aplicación del principio de proporcionalidad en el caso previo.

\section{BIBLIOGRAFÍA CITADA}

Abril, Ernesto (2007): "Sobre el sentido de los límites jurídicos”, Anuario del CIJS, vol. X: pp. 551-572.

Aleinikoff, Alexander (1987): "Constitutional Law in the Age of Balancing”, The Yale Law Journal, vol. 96: pp. 943-1005.

AleXY, Robert (1997): Teoría de los derechos fundamentales (trad. Ernesto Garzón Valdez, Madrid, Centro de Estudios Políticos y Constitucionales).

Alexy, Robert (2002): "Epílogo a la Teoría de los Derechos Fundamentales”, Revista Española de Derecho Constitucional, Año 22, No 66: pp. 13-64.

Alexy, Robert (2008): "La fórmula del peso", en Carbonell, Miguel (edit.), El principio de proporcionalidad y la interpretación constitucional (Quito, Ministerio de Justicia y Derechos Humanos) pp. 13-42.

Alvira, Tomás, Clavell, Luis y Melendo, Tomás (1986): Metafísica (Pamplona, Eunsa). 
Arnold, Rainier, Martínez-Estay, José Ignacio y Zúñiga Urbina, Francisco (2012): “El principio de proporcionalidad en la jurisprudencia del Tribunal Constitucional”, Estudios Constitucionales, Año 10, N 1: pp. 65-116.

AtienZa, Manuel (2010): “A vueltas con la ponderación. La Razón del Derecho”, Revista interdisciplinaria de Ciencias Jurídicas, vol. 1: pp. 1-15.

Ávila, Humberto (2011): Teoría de los principios (Madrid, Marcial Pons).

Beatty, David M. (2004): The Ultimate Rule of Law (New York, Oxford University Press).

Bernal Pulido, Carlos (2008): "La racionalidad de la ponderación", en Carbonell, Miguel (edit.), El principio de proporcionalidad y la interpretación constitucional (Quito, Ministerio de Justicia y Derechos Humanos) pp. 43-68.

Bethge, Herbert (1977): Zur Problematik von Grundrechtskollisionen (Munich, Franz Vahlen).

Betterman, Karl (1964): Die allgemaine Gesetze als Schranken der Pressefreiheit (Juristenzeitung).

Borowski, Martin (2013): “On Apples and Oranges. Comment on Niels Petersen”, German Law Journal, vol. 14, No 8: pp. 1409-1418.

Carbonell, Miguel (edit.). (2008): El principio de proporcionalidad y la interpretación constitucional (Quito, Ministerio de Justicia y Derechos Humanos).

Cardona, Caros (1973): Metafísica de la opción intelectual (Madrid, Rialp).

Celano, Bruno (2002): "Defeasibility e bilanciamento. Sulla posibilita di revisión stabili", Ragione Prattica, vol. 18: pp. 223-239.

Cianciardo, Juan (2009a): El principio de razonabilidad (Buenos Aires, Depalma, segunda edición).

Cianciardo, Juan (2009b): Principio de proporcionalidad y concepto de derecho (Buenos Aires, Ad-Hoc).

Cianciardo, Juan (s.f.): "El principio de proporcionalidad y sus límites", en Revista Argentina de Derecho Administrativo (en prensa).

Covarrubias Cuevas, Ignacio (2012): "La desproporción del test de proporcionalidad: aspectos problemáticos en su formulación y aplicación", Revista Chilena de Derecho, vol. 39, $\mathrm{N}^{\circ} 2$ : pp. 447-480.

Covarrubias Cuevas, Ignacio (2014): “¿Emplea el Tribunal Constitucional el test de proporcionalidad”, Estudios Constitucionales, año 12, Nº 1: pp. 163-237.

DA Silva, Alfonso (2003): Grundrechte und gesetzgeberische Spielräume (Baden-Baden, Nomos).

De Lora, Pablo (2000): “Tras el rastro de la ponderación”, Revista Española de Derecho Constitucional, vol. 60: pp. 359-369.

Elster, Jon (1999): Juicios salomónicos. Las limitaciones de la racionalidad como principio de decisión (trad. Carlos Gardini, Barcelona, Gedisa).

Finnis, John (1997): “Commensuration and Public Reason”, en CHAnG, Ruth (edit.) Incommensurability, Incompatibility, and Practical Reason (Massachusetts, Harvard University).

Frantz, Laurent (1963): "Is the First Amendment Law? - A Reply to Professor Mendelssohn”, California Law Review, vol. 51: pp. 748 y ss.

García Amado, Juan Antonio (1996/1997): “¿Ductilidad del derecho o exaltación del juez? Defensa de la ley frente a (otros) valores y principios", Archivo de Filosofía del Derecho, t. XIII-XIV. 
García López, Jesús (1995): Lecciones de metafísica tomista (Pamplona, Eunsa).

GAST, Wolfgang (2006): Juristische Rhetorik (Heidelberg, C. F. Müller, cuarta edición).

Gavara de Cara, Juan Carlos (1994): Derechos fundamentales y desarrollo legislativo. La garantía del contenido esencial de los derechos fundamentales en la Ley Fundamental de Bonn (Madrid, Centro de Estudios Constitucionales).

Gordillo, Agustín (2004): Tratado de derecho administrativo, Tomo III (Buenos Aires, Fundación de Derecho administrativo).

GüNTHER, Klaus (1988): Der Sinn für Angemessenheit (Frankfurt am Main, Suhrkamp).

Habermas, Jürgen (1996): "Anhang zu Faktizität und Geltung. Replik auf Beiträge zu einem Symposion der Cardozo Law School”, en Id., Die Einbeziehung des Anderen. Studien zur politischen Theorie (Frankfurt am Main: Suhrkamp).

Habermas, Jürgen (2008): Facticidad y validez (Madrid, Trotta, quinta edición).

HART, Hebert (1951): "The Ascription of Responsibility and Rights", en Flew, Antony, Logic and Language (Oxford, Blackwell) pp. 145-166.

Henkin, Louis (1978): "Infallibility under Law: Constitutional Balancing", Columbia Law Review, vol. 78: pp. 1022-1049.

Hervada XiberTa, Javier (2001): Introducción critica al Derecho natural (Pamplona, Eunsa, décima edición).

Hirschberg, Lothar (1981): Der Grundsatz der Verhältnismäßigkeit (Gotinga, Otto Schwartz \& Co.).

JANSEN, Nils (1997): "Die Struktur rationaler Abwägungen“, ARSP, suplemento 66: pp. 152-168.

Jezé, Gastón (1950): Principios generales del derecho administrativo, Tomo V (Buenos Aires, Depalma).

(1980): Discurso a la Rota Romana de 4-II-1980 (AAS, vol.72: pp. 172-178).

Klatt, Matthias \& MeIster, Moritz (2014): The constitutional structure of proportionality (Oxford, Oxford University Press).

LEISNER, Walter (1997a): “Abwägung überall - Gefahr für den Rechtsstaat”, NJW, vol. 10: pp. 636-639.

LEISNER, Walter (1997b): Der Abwägungsstaat (Berlín, Duncker \& Humblot).

Llano, Alejandro (1984): Gnoseología (Pamplona, EUNSA).

Lopera Mesa, Gloria (2006): Principio de proporcionalidad y ley penal (Madrid, Centro de Estudios Políticos y Constitucionales).

Lopera Mesa, Gloria Patricia (2008): "Principio de proporcionalidad y control constitucional de las leyes penales", en CARBOnell, Miguel (edit.), El principio de proporcionalidad y la interpretación constitucional (Quito, Ministerio de Justicia y Derechos Humanos) pp. 269-306.

Maldonado Muñoz, Mauricio (2012): "El principio de razonabilidad y su aplicación al estudio de validez de las normas jurídicas”, Ius Humani. Revista de Derecho, vol. 3: pp. 139-174.

Maldonado Muñoz, Mauricio (2014): "La intangibilidad de las acciones privadas de las personas", Ius Humani. Revista de Derecho, vol. 4: pp. 9-48. 
Mestre Delgado, Juan Francisco (1985): “La posición singular de la administración en la contratación administrativa y las garantías del contratista según la jurisprudencia contencioso-administrativa reciente", Revista Española de Derecho Administrativo, vol. 47: pp. 425 y ss.

Moreso, Juan José (2003): “Conflictos entre principios constitucionales”, en Carbonell, Miguel (edit.), Neoconstitucionalismo(s) (Madrid, Trotta) pp. 99-122.

Moreso, Juan José (2008): “Alexy y la aritmética de la ponderación”, en CARBOnell, Miguel (edit.) El principio de proporcionalidad y la interpretación constitucional (Quito, Ministerio de Justicia y Derechos Humanos) pp. 69-83.

OssenbÜHL, Fritz (1995): "Abwägung im Verfassungsrecht” (Deutsche Verwaltungsblatt).

Pío XII (1942): Discurso a la Rota Romana de 1-X-1942 (AAS, vol. 34: pp. 338-343).

Polo Barrena, Leonardo (2002): Introducción a la Filosofía (Pamplona, Eunsa, tercera edición).

Portocarrero Quispe, J.A. (2011): Peligros y límites de la ponderación (Lima, Universidad Nacional Mayor de San Marcos, tesis).

Raz, Joseph (2001): "Incommensurability and Agency", en Id., Engaging Reason (Oxford, Oxford University Press).

RHONHEIMER, Martin (2000): La perspectiva de la moral (Madrid, Rialp).

SAPAG, Mariano (2012): "Interpretación constitucional y control de razonabilidad. Elementos para la comprensión general y aplicación práctica del principio de razonabilidad”, en Cianciardo, Juan (edit.), Constitución, Neoconstitucionalismo y derechos (México, Porrúa) pp. 171-206.

SCHLInK, Bernhard (1976): Abwägung im Verfassungsrecht (Berlín, Duncker \& Humblot).

SCHLINK, Bernhard (2001): "Der Grundsatz der Verhältnismäßigkeit", en BADURA y DreIER (edits.). Festschrift 50 Jahre Bundesverfassungsgericht (Tubinga: Mohr-Siebeck) pp. 445-465.

SchneIDER, Harald (1979): Die Güterabwägung des Bundesverfassungsgericht bei Grundrechtskonflikten (Baden-Baden, Nomos).

Serna, Pedro (2003): "Hermenéutica jurídica y relativismo. Una aproximación desde el pensamiento de Arthur Kaufmann”, en Zapatero, Virgilio (edit.), Horizontes de la Filosofía del Derecho. Homenaje a Luis García San Miguel, vol. 2 (Alcalá, Universidad) pp. 737-766.

STELzER, Manfred (1991): Das Wesensgehaltsargument und Grundsatz der Verhältnismäßigkeit (Viena, Springer Verlag).

Stern, Klaus (1994): Das Staatsrecht der Bundesrepublik Deutschland, t. III/2. Allgemeine Lehren der Grundrechte (München, C. H. Beck).

Toller, Fernando (2012): "Los derechos in concert", en Cianciardo, Juan (edit.), Constitución, Neoconstitucionalismo y derechos (México D.F., Porrúa) pp. 111-155.

TRIBE, Laurence (1985): “Constitutional Calculus: Equal Justice or Economic Efficiency”, Harvard Law Review, vol. 98: pp. 592-621.

Willoughby, Westel Woodbury \& Rogers, Lindsay (1924): An Introduction to the Problem of Government (New York, Doubleday, Page \& Company).

ZúNiga AÑAZCo, Yanira (2010): "El principio de proporcionalidad como herramienta de racionalidad. Un análisis crítico de su aplicación en la jurisprudencia del Tribunal Constitucional chileno", Ius et Praxis, año 16, No 2: pp. 249-272. 
